\title{
ADOPTION OF GEOSPATIAL SYSTEMS TOWARDS EVOLVING SUSTAINABLE HIMALAYAN MOUNTAIN DEVELOPMENT
}

\author{
M.S.R. Murthy, Birendra Bajracharya, Sudip Pradhan, Basanta Shrestha, Rajan Bajracharya, Kiran Shakya, \\ Sebastian Wesselman, Mostafa Ali, Sameer Bajracharya and Suyesh Pradhan \\ a International Centre for Integrated Mountain Development (ICIMOD), GPO 3226, Khumaltar, Nepal \\ manchiraju.murthy, birendra.bajracharya, basanta.shrestha @icimod.org
}

\section{Commission TC VIII}

KEY WORDS: Geographic Information; Mountain GIS Portal; Mountain environment.

\begin{abstract}
:
Natural resources dependence of mountain communities, rapid social and developmental changes, disaster proneness and climate change are conceived as the critical factors regulating sustainable Himalayan mountain development. The Himalayan region posed by typical geographic settings, diverse physical and cultural diversity present a formidable challenge to collect and manage data, information and understands varied socio-ecological settings. Recent advances in earth observation, near real-time data, in-situ measurements and in combination of information and communication technology have transformed the way we collect, process, and generate information and how we use such information for societal benefits.
\end{abstract}

Glacier dynamics, land cover changes, disaster risk reduction systems, food security and ecosystem conservation are a few thematic areas where geospatial information and knowledge have significantly contributed to informed decision making systems over the region. The emergence and adoption of near-real time systems, unmanned aerial vehicles (UAV), board-scale citizen science (crowd-sourcing), mobile services and mapping, and cloud computing have paved the way towards developing automated environmental monitoring systems, enhanced scientific understanding of geophysical and biophysical processes, coupled management of socio-ecological systems and community based adaptation models tailored to mountain specific environment.

There are differentiated capacities among the ICIMOD regional member countries with regard to utilization of earth observation and geospatial technologies. The region can greatly benefit from a coordinated and collaborative approach to capture the opportunities offered by earth observation and geospatial technologies. The regional level data sharing, knowledge exchange, and Himalayan GEO supporting geospatial platforms, spatial data infrastructure, unique region specific satellite systems to address trans-boundary challenges would go a long way in evolving sustainable Himalayan livelihoods.

\section{INTRODUCTION}

The geospatial application to the mountain environment involves specific considerations and, much depends on the knowledge of particular characteristics and our understanding of how mountain systems work (Shrestha B. and Bajracharya B., 2011). Addressing mountain development challenges require spatial and temporal data in ranges of regional issues whether it is assessing impact of climate change on glaciers, determining water availability scenarios in river basins, devising conservation strategy for landscape, issuing flood early warning and estimating carbon financing for communities. In addition, free access to information, data sharing and exchange has been limited in the greater Himalayan region due to lack of appropriate regional framework and mechanism.

International Centre for Integrated Mountain Development (ICIMOD) increase emphasise on mainstreaming earth observation and geospatial technologies to its programs and enhancing inter and trans-disciplinary approaches to solve mountain development problems. Outcomes along similar lines had prevailed out of other global summits like Eye on Earth Summit (2011), UN-Geospatial Information Management Directives (2011), GEOSS (2005), emphasizing the importance of geospatial science and technology and harnessing its potentials for the societal benefits. Strategic alliances of ICIMOD build with several global programmes such as GCOS, GEOSS, GTOS, WGMS/GLIMS, WMO and space agencies such as JAXA, ESA, NASA including regional space agencies in China and India.

ICIMOD as a regional knowledge enabling and learning centre has been striving to transform the greater Himalayan region from "data deficit" to "data sufficient" region by implementing comprehensive regional programmes and promoting active regional cooperation among the member countries. Geospatial Solutions augment its regional capability to mainstream geospatial solutions in order to bridge the knowledge gap on regional priorities. To this effect, ICIMOD consolidated its human capital having full-fledged competencies in geospatial science and technology as well as strengthen its state-of-the-art geo-ICT facility. Recent revamping of a Regional Database System (RDS) acts as a central data repository for different thematic areas and provides easy access to these data. The system is assuming greater significance at the global, regional and national levels.

With the use of latest geospatial solutions and communication technologies particularly the mobile services and internet it is working towards reaching a wider audience in the region which are otherwise inaccessible. Ultimately, our aims to advance information science for increased understanding of mountain systems thereby supporting effective actions on the ground as well as contribute to global knowledge on the mountain systems of the greater Himalayan region. 


\section{GEOSPATIAL APPLICATIONS AND DECISION SUPPORT SYSTEMS}

In the Hindu Kush-Himalayans (HKH) region, multi-scale geospatial technique has been enabled mapping, studying, monitoring and management of various resources like agriculture, forestry, snow and water etc. It has been further enabled to monitoring of environmental issue and thereby helping in conservation and mitigation. At ICIMOD some of the important activities carried out in the region Land cover mapping, landscape planning and biodiversity conservation agriculture monitoring including drought forecasting, forest cover mapping and monitoring, rangeland mapping, disaster allocation and snow \& glacier studies. The information generated by large number of projects have been used by various departments, industries and others for different purposes like development planning, monitoring, conservation etc.

\subsection{Land Cover Dynamics - Developmental planning}

In the last few decades the HKH region has undergone rapid economic, social, and environmental changes. Land cover and its change analysis across Hindu Kush Himalayan region is realized as an urgent need to support diverse issues of environmental conservation, climate change adaptation and mitigation options. However, there is a lack of cohesive information on these changes and how they are impacting on land cover and land cover change. In this context ICIMOD has given priority to developed land cover data regional level to micro watershed level using multi sensor remote sensing data.

In the past few years, ICIMOD developed regional level land cover for eastern Himalaya as illustrated in figure 1, country level of land cover for Bangladesh, Bhutan, Nepal, Pakistan and Myanmar; landscape level land cover for Brahmaputra-Salween Landscape, Kanchenjunga Landscape and Kailash Sacred Landscape; river basin level for Koshi Basin; protected and watershed level for Sagarmatha National Park, Karakoram National Park, Qomolangma National Nature Preserve, Phobjikha Conservation Area, Koshi Tappu Wildlife Reserve, Api-Nampa Conservation Area, Mustang, Jumla, Chitwan, Gorkha and Dolakha. The land cover dynamics information is now effectively used for assessment of carbon flux estimations, river basin planning, protected area management, community forest monitoring, trans-boundary landscape studies and climate change adaptation and mitigation studies. Figure -1 depicts forest carbon flux dynamics made over Nepal for the period 1990-2010 using land cover change data as one of the crucial input http://apps.geoportal.icimod.org/NepalLandcover/

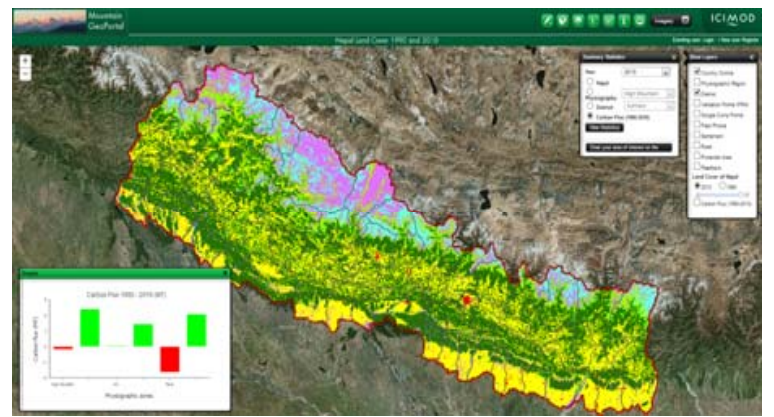

Figure 1: Interactive map on forest cover change and carbon fluxes of Nepal

\subsection{Traditional livelihoods and Food Security}

Agriculture is most important livelihood sector in the Hindu Kush Himalayan region and provides a substantial proportion of rural income and employment opportunities to its estimated 210 million inhabitants. The dramatic climatic and environmental changes, socio-economic changes including economic globalization, increasing accessibility, land use conflicts, geographical constraints often restricting the flow of goods dynamic demography is affecting the agriculture systems across HKH region. A few of the basic challenges addressing food security in the region lies on how to improve the underlying productivity of natural resources and cropping systems to meet increasing farmers demand and to produce food which is safe, wholesome and nutritious and promotes human well-being.

Recent developments in use of earth observation satellite data in combination with ground based information, are being used to reveal valuable information about environmental conditions, crop types and net sown area assessment, crop-water relations, crop productivity that can subsequently impact the livelihoods of farmers. Satellite Crop monitoring tool being adopted over Terai region, Nepal uses historical climate and crop condition patterns and compares this with the current growing season to provide timely assessment of crop growth http://apps.geoportal.icimod.org/agricultureatlas/atlas/ This kind of information is used by concerned line departments to identify regions experiencing unfavourable crop growing conditions and food supply shortfalls and to determine food insecure areas and/or populations.

The development of multifunctional agriculture systems, sustainable management of mountain agriculture practices such as terrace agriculture, shifting cultivation, developing narrow climate and geographic niche based local cropping systems, evolving resilient productive systems against climate disasters, improving water efficient and high crop intensity regimes in low elevations are a few priority areas which requires scientific support and policy level interventions on a continual basis. Similarly increase in use of information communications technologies (ICTs) in facilitating rural development by providing agricultural extension services and real-time market price information, availability of rural payphone is also playing a significant role in enhancing the ability of rural families to continue, and perhaps enhance their contribution to national agricultural production and post-harvest activities.

\subsection{Too much or too little Water - Ensuring Water Security:}

The region has always had either too much or too little water. Water availability has always been markedly seasonal, varying greatly over short distances. For example, about $80 \%$ of the precipitation in Nepal falls within four months of the year; and much of this falls during a few extremely intense rainfall events. Most of it flows quickly through the watersheds and basins of the high mountains and middle hills, causing floods and havoc without much replenishment of groundwater and other natural reservoirs. During the rest of the year, the population struggles to support household needs, agriculture, and industrial demands with too little water. Added to this, climate change dynamics and associated impacts through accelerated melting of snow and glacier ,glacier lake developments and out bursts, flash floods has made the water management in the region complex. 
An integrated river basin studies are planned across different basins is planned with initial focus on Koshi and Indus basins. The studies helps to develop reliable scientific knowledge on river basin dynamics in terms river flow dynamics at different spatial and temporal scales, erosion and sedimentation dynamics, water related hazards, water budgeting and use, water vulnerability and livelihood adaptation options. The outputs are expected to support informed decision making over trans-boundary river basin management, developmental planning for hydro power plants, disaster risk reduction from water related hazards and crop water management. Geospatial data and models are effectively used in this context to understand climate change and variability; cryosphere dynamics; the hydrological regime and water availability; water-related risk management; mountain community water management; and vulnerability and adaptation.

\subsection{Disaster Risk Reduction Systems - Safeguarding Livelihoods}

Hindu Kush Himalaya (HKH) region is predisposed to different types of natural hazards due to geographical and geological setting. Being a youngest and loftiest mountain range of the world, it is geo-morphologically dynamic, climatically sensitive, and geologically and ecologically fragile, making it hot spot of natural hazards. Between 1900 to 2012 countries across HKH region has witnessed 1912 incidents of major disaster events1 resulting in 9,02,2797 deaths and economic damage worth USD 4,59,937.00 (EM-DAT). The trend over the decade is increasing and so is the cost, directly undermining incentives of development. There is a need to refocus our effort on developing action strategies for disaster risk reduction (DRR) in a regional framework, and invest on making available technological leverages for the larger benefit of mountain communities across the HKH region through collaborative framework.

Significant development have taken place across HKH region to adopt near real time geospatial information for emergency disaster response to support large scale disaster event like Koshi breach (2008), Pakistan floods (2010), Jammu and Kashmir floods (2014). The establishment of ground based automated flow recording system like (HKH-HYCOS), advancements in satellite and model based rainfall and flow estimations and flood forecast, inundation modelling and visualisation and community based early warning systems operational forest fire alert systems in India, China, Nepal and Bhutan, satellite based drought and crop monitoring systems and Multi scale Disaster Information Systems are some of the standing developments supporting many disaster risk reduction activities.

Most of the DRR activities currently are dependent on different types of models that simulate reality and help us to prepare for the eventuality. However, with the climate extremes adding element of surprises and complex physics behind it, uncertainties in prediction of disaster events - both timing and intensity, is undermining our preparedness investment and eroding away developmental gains made over years of tireless effort. The climate change - disaster event nexus is more prominent here in the context of hydro-meteorological disaster events. The unprecedented scale of flood events in the past Pakistan flood of 2010 and Uttarkhand flood of 2012 are some of events as testimony to elude link between weather system and disaster. Despite the increased adoption of scientific and technical knowledge, large gap exists to overcome challenges associated with unpredictability. There is a stronger need to further harness science and technological leverages to our advantages and seek solutions from cutting edge geospatial tools and systems.

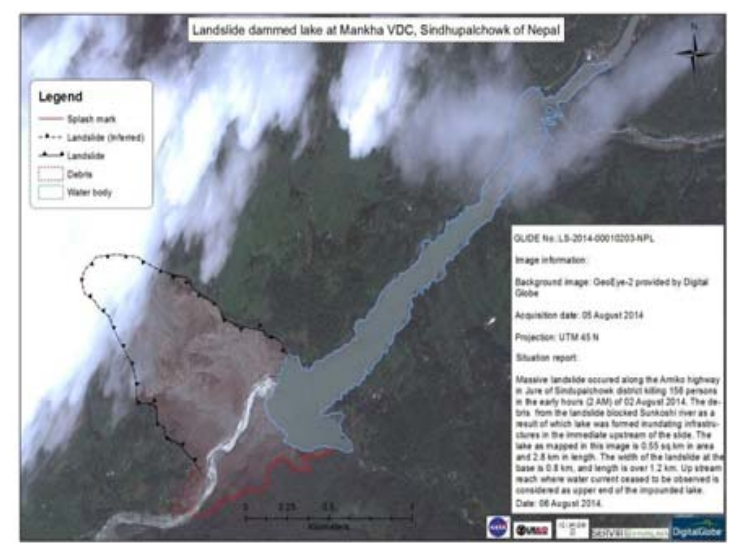

Figure 2: Map of Sunkoshi landslide and dammed Lake of August 5, 2014.

\subsection{Trans-boundary landscapes - Conservation and Development:}

The HKH region is well known for geo-hydrological, biological, cultural, and aesthetic values. A wide range of ecosystems provide numerous services including climate regulation and goods such as water, food, and biodiversity. Most of these ecosystems are subject to climatic and nonclimatic changes which are affecting their functioning and sustainability and thereby the livelihoods and resilience of communities living in the region as well as in downstream areas. Ecosystems can be managed sustainably only by following an integrated approach that recognizes their transboundary nature and the flow of services beyond administrative boundaries. Trans-boundary landscapes are better conserved and managed for sustaining ecosystem goods and services to improve livelihoods and enhance ecological integrity, economic development, and socio-cultural resilience to environmental changes.

In this context, Wakhan, Karakoram, Kailash, Everest, Kanchenjunga, Brahmaputra-Salween and CherapunjeeChittagong) Trans-boundary landscapes and transects were delineated engaging regional, national, and local partners and the global research community and encourage regional cooperation and national ownership to build and enhance capacity for long-term environmental and ecological research and monitoring across the Hindu Kush-Himalayan (HKH) region. About $20 \%$ of the protected areas are trans-boundary in nature having contiguous habitat across the political border requiring regional cooperation to conserve such wilderness. Geospatial techniques are adopted to study land cover dynamics and change simulation, vegetation composition and productivity assessment, trans boundary corridor designing and habitat suitability analysis, understanding climate and non-climate drivers on ecosystem structure and function, community based conservation planning and development and long term socioecological monitoring. 


\subsection{Glacier dynamics - Environmental and Social Challenges}

The Hindu Kush Himalayan (HKH) region, often referred to as the Third Pole, contains the world's greatest areal extent and volume of permanent ice and permafrost outside the Polar Regions. This vast accumulation of snow and glaciers acts as a natural water reserve, which serves as a water source for approximately 1.3 billion inhabitants in the 10 major Asian river basins downstream. Rising temperatures, especially at higher altitudes, are playing a role in rapid glacier melt, increased frequency and magnitude of associated extreme weather events, and shifts in monsoon patterns. These changes impact the availability of water for agriculture, domestic needs, industry, and hydropower.

Considering this importance, comprehensive digital inventory of glaciers was made using remote sensing data to number more than 54,000 covering an area of $60,000 \mathrm{~km}^{2}$. Glaciers were analysed for area, elevation range, slope, and aspect. In addition, 28,500 glaciers with a total area of $32,000 \mathrm{~km}^{2}$ were analysed for debris cover, morphology, and hypsometry (Bajracharya and Shrestha, 2011). The data are expected to support regional level assessments and the development of strategies and policies in the context of climate change, and will also contribute to increased understanding of the impacts of climate change on glaciers and the implications for the mountain ecosystem and for water availability in the downstream countries.

\section{ENABLING TECHNOLOGIES AND OPPORTUNITIES}

The phenomenal growth of mobile telephone use, internet connectivity, open source real time geospatial information have been realized as one of the valuable assets to meaningfully collect, package and deliver information and knowledge to well informed and inaccessible rural people.

In other hand, the available data are still fragmented, heterogeneous and not easily accessible to the people since data sharing is still a sensitive and complicated issue in the region (Shrestha B. and Bajracharya B., 2011). Despite such hindrances, there is already a wide range of freely available data and enabling technologies that fulfils gaps in data, data standards and data sharing protocols so that resources can be saved from duplications and societies can benefit from the easy access to data. Such data at global, regional or national scale at different frequencies can be used to understand some of the ecological and environmental issues in the region. Significant progress has been made across the globe in harnessing the potential of mobile technology in the sectors of natural resources management and disasters. Some of the effort in this area is forest fire alert system, advisory service in agriculture, innovative and crowd-sourcing application such as mapping brick kiln, agriculture land, and community forest in Nepal, flood alert system in Bangladesh and emergency response and disaster management.

\subsection{Geo Visualisation and Information System:}

The Himalayan region is witnessing rapid environmental and societal changes placing pressures on sustainable mountain development. Right information, Right communication, Right time and Right audience are the four foundations which have greatest leverage for our improved understanding of the changes and guide our policies and programmes of regional significance. There is a strong need to develop data infrastructure, sharing mechanism and ability to integrate diverse multidisciplinary domains and turn it into understandable information for intended audiences at right time.

A new wave of technological innovations allows us to capture, synthesize, visualize and communicate unprecedented amount of data and information which are often proved difficult in remote and inaccessible mountain areas (Fig-3). ICIMOD has a proven track-record of utilizing remote sensing and geographic information technologies and recognized as a regional "centre of excellence” with a special mountain focus.

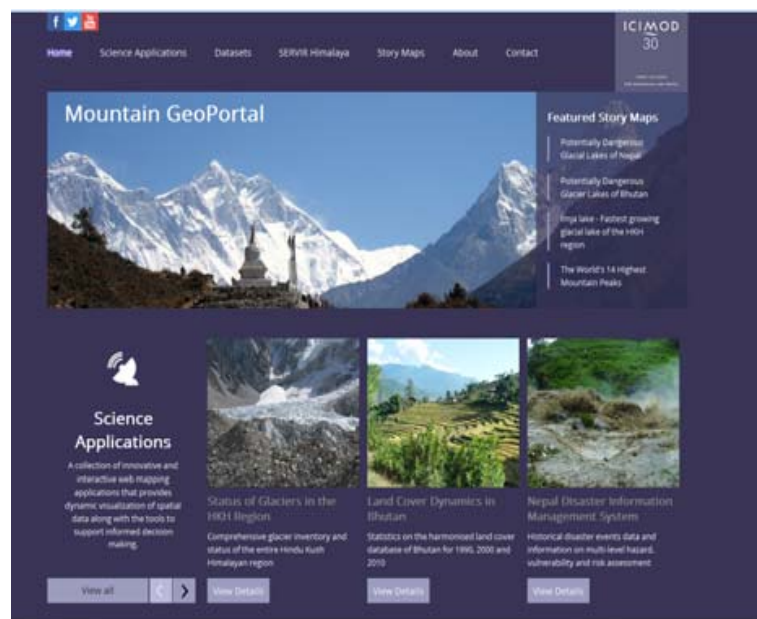

Figure 3: The Mountain Geo Portal

An advanced geo visualization and information systems are being developed with an aim of providing improved data acquisition, access to relevant information and knowledge and capacities to use them effectively by the end-user communities. The mountain geo portal is serving as a GIS resources that ICIMOD had developed together with network of national partners in the region. More importantly, it is a common platform to access and share information and knowledge about the advance GIS technology and its applications in mountain development. In realization to the importance of geospatial data, National geospatial platform are being initiated to share, discovery, retrieval and visualize data at national levels.

\subsection{Regional database initiative}

Regional Database System (RDS) - which are available at http://rds.icimod.org that integrates data and information incorporating geospatial, socio-economic and multi-thematic data at different levels. This initiative is working on appropriate policies to facilitate data and information sharing as well as on technical specifications for design, development and management of data and information systems, enabling data use beyond the original research, and has been aligned with the philosophy of open and free access to scientific information and knowledge.

\subsection{Unmanned Aerial Systems (UAS) and citizen science}

Unmanned Aerial Systems (UAS) and citizen science is revolutionizing scientific data collection efforts like monitoring agricultural crops and community forest, disaster site and 
glacier monitoring (Immerzeel et al., 2014), bridging the data gap and the costs of monitoring, rugged terrain and, ultimately, better protecting ecosystem and food security(Fig-4) .

Engaging communities and citizens to generate data e.g. taking photography in mass scale for the purpose of understanding science and nature is still a relatively new and evolving approach in the region. However, a lot of initiatives are taking place, e.g. photo database along The Great Himalayan Trail, environmental monitoring and open street mapping to this effect which is also termed as crowd-sourcing.

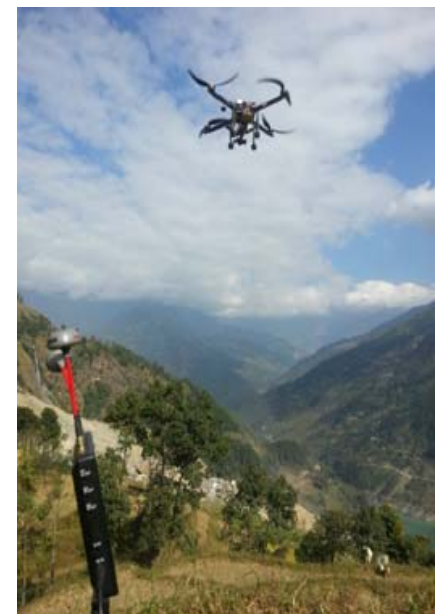

Figure 4: Damage assessment using UAV in Jure landslide, Nepal

\subsection{Socio-Ecological coupling: Agent based modelling}

The studies focusing on livelihood improvement embark upon linking diverse biophysical and social-ecological data of different spatial and temporal dimension to quantify and understand patterns, trends and inter linkages. This understanding is expected to derive, infer and develop knowledge base supporting different resource conservation and adaptation strategies at multiple scales. A vast body of literature on agent-based modelling (ABM) shows it's potential to couple social and environmental models, to incorporate the influence of micro-level decision making in the system dynamics and to study the emergence of collective responses to policies and facilitate decision making. The agent models supports to integrate human behaviour under different climate and nonclimate drivers of change, policy and governance regimes and variable socio-economic development scenario in optimal use of natural resources and adopting to different climate change risks. Developing optimal fuel wood use, transhumance grazing, water consumption and land cover change simulations are a few applications are being studied to address livelihood improvement strategies.

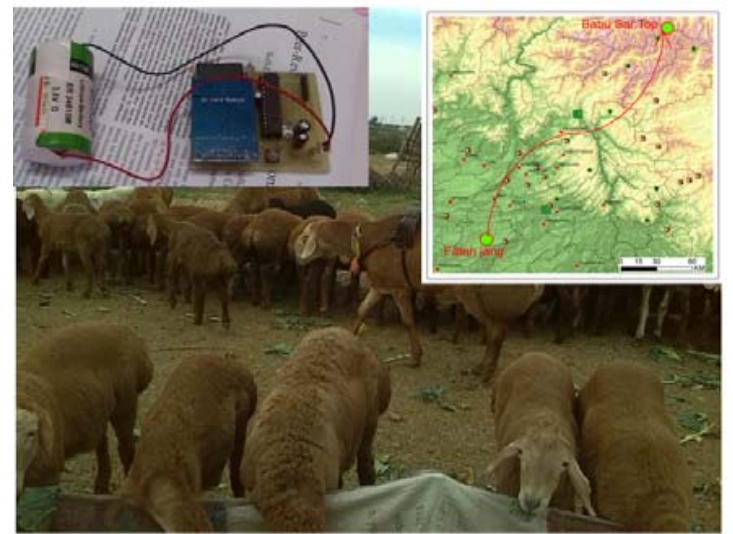

Figure 5: Understanding spatio-temporal patterns of transhumance grazing in Upper Indus Basin.

\subsection{Climate Smart Strategies - Low Cost Innovations:}

In order to ensure that development is resilient to climate change, it is imperative that we integrate climate risk considerations into policy and enable innovative solutions. Innovation at micro and macro levels is essential for promoting climate-smart strategies. However, until now the focus has been mostly on commercial, top-down technological innovation and those involved in bottom-up innovation often do not have the capacity to overcome barriers to make this innovation visible. Low cost, user friendly climate-smart strategies that build the social and physical resilience of societies are the need of the hour.

Diverse geospatial tool and techniques are being developed to integrate with ground based strategies to evolve climate change adaptation and mitigation options in the areas of community forestry, optimal grazing plans, and integrated farmer advisory systems. The integration of GPS, mobile phones, low cost community based forest measurement tools, UAVs, consortium based use of low cost satellite data, community GIS tools are being integrated to provide low cost technology for rapid damage assessment and environmental monitoring (Figure 6). The tracking sheep mobility across different climate and productivity gradients of grasslands using locally made GPS collars, local indigenous and traditional knowledge, open source satellite based grassland phenology and productivity are interactively used to develop climate smart tools for optimal grazing plans as part of climate change adaptation strategies (Figure 5).

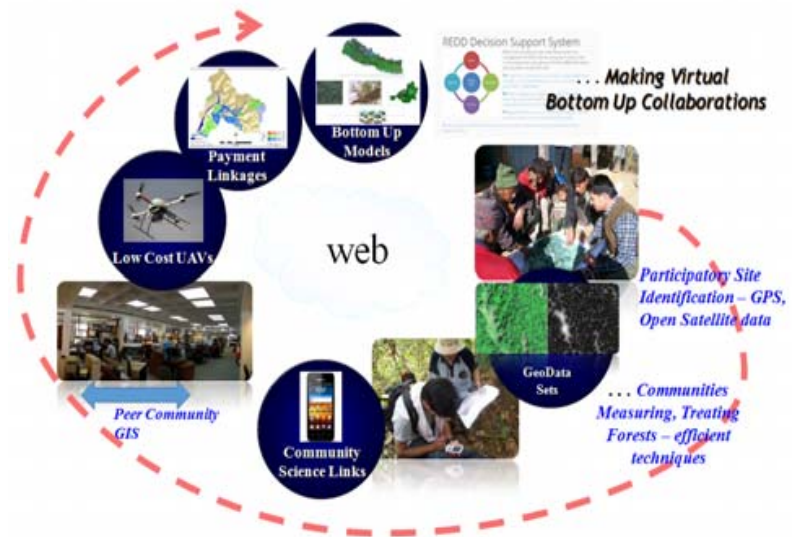

Figure 6: Low cost technologies, web community, forest conservation and monitoring 


\section{CAPACITY BUILDING}

The capacity building in understanding and application of geospatial science across $\mathrm{HKH}$ region stands as one of the major achievement over the last two decades. Considering geospatial systems and knowledge as one of the critical bridging mechanisms to understand and develop practical solutions and policy support, the capacity building in this discipline of science need to be augmented with multidimensional approach. Strategic training, Focus on priorities of partners, Trainings customized to project needs, Co-organizing with reputed organizations, on the job training, collaboration with specific expertise and regional networking, and Youth engagement are a few of the diverse approaches being planned through vibrant capacity building window of SERVIRHIMALAYA.

In order to gain full acceptance and momentum towards full implementation of tools and services within institutions, commitment at the management level should be assured as a first priority. Towards this a number of strategic and policy level participant trainings are organised. When commitment at the management level was assured, this has resulted in increased participation in training events and uptake of knowledge, tools and services within the partner institutions. Customized approaches and trainings are also given to build capacities over priority thematic areas as well as gaps among partner institutions. The mechanism of engaging partnerships with reputed international agencies is also followed to create additional synergies and generally lifting the profile of the event, thus creating a more conducive learning environment.

To make sure our future generation is well equipped with knowledge and technical skills regarding Earth Observation and geospatial technologies, an important part of SERVIR Himalaya's capacity building efforts is related to youth. Through internships, youth forums, Hackathons and special scholarship programmes as MyCoe, youth gets empowered with the use of Earth Observation and geospatial applications. Collaboration with academic institutions is useful for a number of reasons; training and research can go hand in hand, personnel turnover is not a major issue and there is the implicit possibility to train trainers and replicate knowledge that is transferred. ICIMOD Himalayan University Consortium is an opportune platform to facilitate collaboration with universities and relevant research institutions.

\section{REGIONAL COOPERATION}

Data sharing, knowledge exchange, cross learning platforms, Himalayan spatial data infrastructure, region specific collaborative earth observation systems, distribute network based integrated web services are a few of the few priority areas for regional collaboration. Such systems would definitely catalyse the efforts in addressing trans-boundary challenges and especially disaster risk reduction systems. It is also necessary to amalgamate such efforts towards evolving Himalayan Mountain GEO in collaboration with GEOS as a more vibrant system to address regional challenges cohesively.

\section{CONCLUSIONS}

Across Himalayan system, regional member countries and international organizations like ICIMOD have launched scientifically sounded river basin and landscape to local scale studies to support certain trans-boundary, national and sub- national issues. However, the systematic observation and evaluation on continual basis addressing pan Himalayan nature facilitating to understand regional, trans-boundary and bioclimatic and climatic regional process is very much lacking. It is also found that there is a greater need to significantly improve the outreach both in terms of professional and amateur users to develop environmental awareness.

Globally there has been a phenomenal increase in access to the open source satellite data, value added information and open source models, high end software and hardware systems to support visualization of high resolution satellite images. This has brought globally a paradigm shift in extending open information services to support different domains of decision making. In this context, considering the potential capabilities of international and regional member countries, it is important to develop open and crowd-source based Himalayan regional monitoring system and promote regional cooperation in data sharing. Participation and partnership are the keys to evolution of information systems for societal benefits.

\section{REFERENCES}

Bajracharya, S.R., Shrestha, B., 2011. The status of glaciers in the Hindu Kush-Himalayan region. International Centre for Integrated Mountain Development (ICIMOD).

Immerzeel, W.W., Kraaijenbrink, P.D.A., Shea, J.M., Shrestha, A.B., Pellicciotti, F., Bierkens, M.F.P., de Jong, S.M., 2014. Highresolution monitoring of Himalayan glacier dynamics using unmanned aerial vehicles. Remote Sensing of Environment 150, 93-103.

Shrestha B., Bajracharya B., 2011. Proceedings of the International Symposium - Benefiting from Earth Observation.

Vedwan, N., Rhoades, R.E., 2001. Climate change in the Western Himalayas of India: a study of local perception and response. Climate Research 19, 109-117. 